http://www.jfas.info

\title{
PRIORITIZATION OF MELLAT BANK'S BRANCHES IN SEMNAN BY MEANS OF ANALYTICAL HIERARCHY PROCESS (AHP) AND WEIGHT CALCULATION TECHNIQUE OF SPECIAL VECTOR
}

\author{
Y. Hemmati* and A. Danaei \\ Islamic Azad University, Faculty of Management, Semnan Branch, Semnan Iran
}

Published online: 15 May 2016

\begin{abstract}
Banks and credit and financial institutions are one of the most effective institutions in economic system of any country, playing a great role in investments in order to advance and promote the countries' economy. The present paper uses the technique of AHP process to measure and compare the various branches of Mellat Bank in Semnan. Its results show that the resources, expenditures, profitability, overdue debts, and electronic services are the most important indicators, which affect the function of Mellat Bank's branches. Afterwards, by means of the technique of specific weight vector each of the indicators and options will be determined. Eventually, using the calculations, results, and applying the existing choices, the branches of Mellat Bank will be prioritized and some suggestions will be presented.
\end{abstract}

Keywords: AHP; specific vector technique; Bank Mellat in Semnan.

Author Correspondence, e-mail: shahid1388@yahoo.com

doi: http://dx.doi.org/10.4314/jfas.v8i3s.191 


\section{INTRODUCTION}

Bank is one of the most important institutions which on one hand provides money, distributes it, and regulates credit, and on the other regulates the monetary policies of the government. Money and bank are a part of a great system, known as financial system, and a part of the society's economic system.

Performance evaluation is a process, beginning with human birth, always trying to amend and promote itself. Nowadays due to the increasing growth of organizations' importance in the society, evaluation of organizations and managers' performance has received more attention than before and various indicators have been presented as its criteria.

The activity of banks is done by small and big branches with the latter having more expanded operation and the former, limited responsibilities which are distributed based on the branches' grading. Hence, grading the banks' branches is an essential matter, having numerous effects on the branches.

On the other hand, one of the most important issues, always faced by the managers, is to evaluate the performance of the units under their supervision while the relative position of each unit is determined among the other units. Therefore, each manager likes to guarantee a clearer horizon of the units under his supervision with the tools of encouragement and punishment.

Determining the branches' position and efficiency can be of high account for the managers, thus the present paper applies the five existing indicators and options and via AHP as well as specific vector techniques, tries to prioritize the branches of Mellat Bank in Semnan.

\section{IMPORTANCE AND NECESSITY OF THE RESEARCH}

Different branches of commercial, governmental, and private banks operate throughout the country and, based on the amount of activities, software and hardware facilities, and geographical location are graded as super, $1^{\text {st }}, 2^{\text {nd }}, 3^{\text {rd }}, 4^{\text {th }}, 5^{\text {th }}$, and $6^{\text {th }}$ degree branches. By determining a branch's rank, its responsibilities will be set and the payments and bonuses of a branch's staff depend on its grade. 
If the branch's grade is determined correctly, it naturally shows that the responsibilities as well as the paid bonuses have been done correctly too; otherwise, if it is not in accordance with right criteria, it definitely will have bad impacts on these determined responsibilities.

If the grade is more or less than the real rate, the responsibilities will be different from reality, the branch's tasks will not be optimal, and the staff will not achieve their real right, which results in some dissatisfaction and without any doubt will bring some problems and bad impacts on the bank's tasks as well.

S. Chaufnite, Rossen, and Parady in Canada studied output variants (the teller, ledger, accounting, supervision, typist, and credits) and input variants (exchange inputs, loan inputs including long-term accounts, and commercial and private loans accounts) (S. Chaufnit, 1997).

Thomas Simes and Richard Bar studied output variants (income, building and facilities, and different fund costs) as well as inputs' variants (properties' interest and earnings before and after interest) in USA banks via data cover analysis (Simes, 1997).

Pezhman Abedi studied the variants of staff number, fixed assets, amount of saving deposits, amount of investment deposits, and amount of other deposits of the private sector as the output, along with the amount of given loans to the private sector as the input variants from the information collected from ten Iranian banks and via random method (Abedi, 2000).

Among social-economic institutions, banks play an essential role in attracting and developing useful and effective capitals of the economic sector. In case of being efficient and effective, they can act as a controlling factor on inflation (by absorbing money supply), a booster of the infrastructures of industrial development (by expanding investment), and a support of capital exchanges to have a useful influence on sustainable development. Hence since grading the inputs and outputs of bank branches is of high account, playing an important role in performance evaluation and feedback of the quality of bank's activity, the current research has been conducted to pave the way to schedule the improvement of the performance and establish the cycle of efficiency. 


\section{LITERATURE REVIEW AND RESEARCH BACKGROUND}

\section{Research's Literature Review}

\section{Final Grading of Decision Making Units by Means of AHP}

Analytical Hierarchy Process (AHP) is one of the most renowned techniques of multi-purpose decision making, first invented by Thoomas L Saaty in 1970s. It can be used when the act of decision making faces some opponent choices as well as decision making criteria (Asghar Pour, 1998).

The mentioned criteria could be either qualitative or quantitative. The foundation of this method is to make decisions based on pair comparisons. The decision maker begins with the decision hierarchy tree, which shows comparison factors and evaluate competing alternatives in the decision. Afterwards a series of paired comparisons are done, which determine the weight of each factor in line with the competing alternatives, and eventually AHP compiles the resultant matrices, from the paired comparisons, in a way, leading to the optimal decision.

\section{Making the Hierarchy Tree of the Decision}

Whenever AHP is used as the decision-making tool, the group should provide an appropriate hierarchy tree, which indicates the problem under study. Decision hierarchy is a tree which in accordance with the problem has numerous levels.

The first level of each tree indicates the decision making's goal while the last one shows the alternatives which are compared to each other and compete for being selected. Also the middle levels indicate the factors which are the criteria of the alternatives' comparison. 


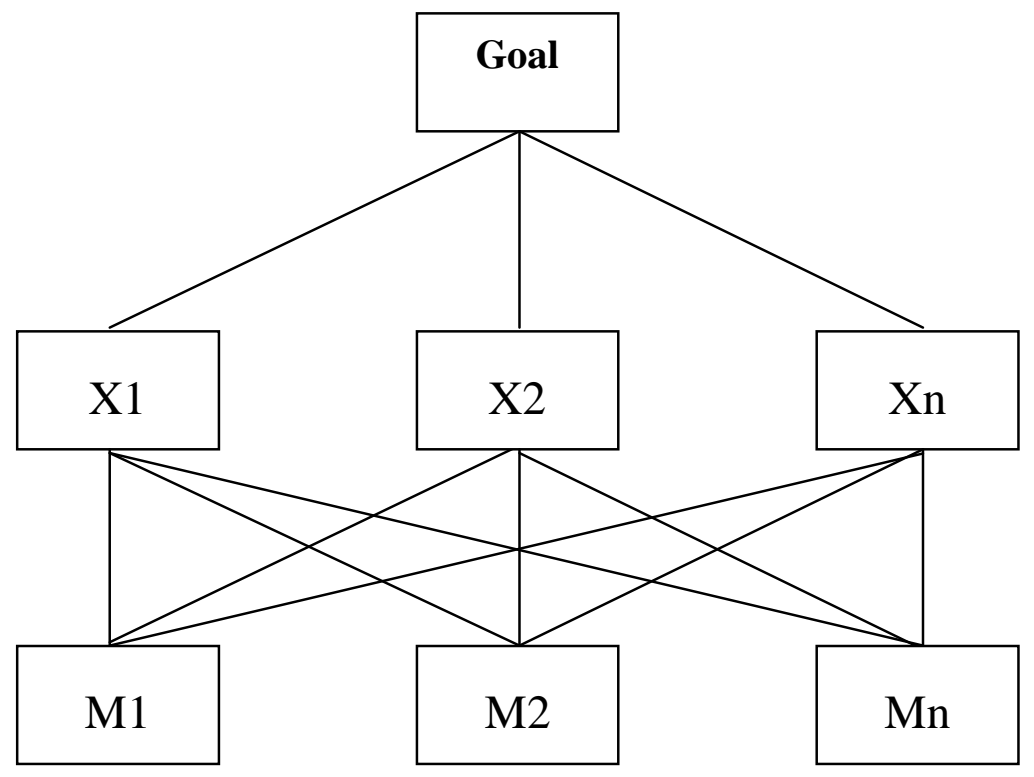

Level 1

Goals

Level 2

Factors

Level 3

Competing alternatives

Chart 1. Hierarchy of the decision tree

The essential stage, in this decision is to determine factors, based on which the competing alternatives are compared to one another. Determining these factors in individual decisions is not much difficult since the decision maker, himself, determines them.

In this stage, using common techniques of group-based decision making could be functional. Usually it is recommended to use the Delphi Technique, in which by distributing questionnaires, experts' opinions are collected and are approved by the majority after some stages, including:

1. Each of the group members are given a questionnaire, separately and privately, which includes all desired factors and they are asked to give a score of 1 to 10 to these factors.

2. A questionnaire, covering the scores of group members in a place, is collected. In this stage there are two methods to determine the final factors: In the first stage factors that have been scores less than 7 by all the members are deleted. The questionnaire is 
corrected once more and is sent to the members to be scored again. These stages repeated again and again until the factors, chosen by consensus are scored higher than 7 .

A faster method is that in the first round, the scores given to each factor is averaged and factors with a score higher than 7 , be selected as the ultimate ones.

After this mathematical operation, AHP starts to reach the goal (the necessary decision) which has been given below.

\section{Stage One) Paired Comparisons:}

The comparison table is established as a hierarchy tree from bottom to the top; in other words, competing alternatives in the second level should be compared in pairs in accordance with each of the factors in that level. This comparison is done by use of a scale, designed from a similar preference to infinite references.

The table below shows the standardized scale of this method.

In this level, organization management faces several differing opinions for each of the factors. There are many methods to compile the opinions into a single one, the commonest of which is to hold a meeting with the organization managers as well as experts so that a consensus is reached. However, one of the best methods is to use a geometrical average since the comparison data are in proportions. What is more, the reverse nature of the comparison matrix justifies the use of this average.

Table 1. Standard Scale of Paired comparisons

\begin{tabular}{llr}
\hline $\begin{array}{l}\text { Importance degree in paired } \\
\text { comparisons }\end{array}$ & $\begin{array}{l}\text { Numerical value of } \\
\text { the score }\end{array}$ \\
\hline Equality Preferred & 1 \\
\hline Equality to Moderately Preferred & 2 \\
\hline Moderately Preferred & 3 \\
\hline Moderately to Strongly Preferred & 4 \\
\hline Strongly Preferred & 5 \\
\hline Strongly to Very Strongly Preferred & 6 \\
\hline
\end{tabular}




\begin{tabular}{lc}
\hline Very Strongly Preferred & 7 \\
\hline Very to Extremely Preferred & 8 \\
\hline Extremely Preferred & 9 \\
\hline
\end{tabular}

Assume that $\mathrm{aij}^{(\mathrm{k})}$ is the component, related to the $\mathrm{k}^{\text {th }}$ individual for the comparison between alternatives $\mathrm{i}$ and $\mathrm{j}$; geometrical average of the corresponding components are measured as below (Adel Azar, 1998).

$$
a i j=\left\{\begin{array}{c}
\left(\begin{array}{c}
\pi \\
k-1
\end{array}{ }^{(k)}\right)^{\frac{1}{N}} \\
\left.2 \quad{ }^{2} a_{k=1}^{w} k\right)^{\frac{1}{N}} ، \sum_{k-1}^{L} W_{R}-N
\end{array}\right.
$$

Where $\mathrm{W}_{\mathrm{R}}$ is the weight of the member's importance.

\section{Special Vector Method}

In order to calculate the weights various methods could be used, in which the $\mathrm{W}_{\mathrm{i}} \mathrm{s}$ are determined in way to comply with the following equations:

$$
\begin{aligned}
& \mathrm{a}_{11} \mathrm{~W}+{ }_{1} \mathrm{a}_{12} \mathrm{~W}+. .+{ }_{2} \mathrm{a}_{1 \mathrm{n}} \mathrm{W}_{\mathrm{n}}=\lambda . \mathrm{W}_{1} \\
& \mathrm{a}_{21} \mathrm{~W}_{1}+\mathrm{a}_{22} \mathrm{~W}_{2}+. .+\mathrm{a}_{2 \mathrm{n}} \mathrm{W}_{\mathrm{n}}=\lambda . \mathrm{W}_{2} \\
& \mathrm{a}_{\mathrm{n} 1} \mathrm{~W}_{1}+\mathrm{a}_{\mathrm{n} 2} \mathrm{~W}_{2}+. .+\mathrm{a}_{\mathrm{nn}} \mathrm{W}_{\mathrm{n}}=\lambda . \mathrm{W}_{\mathrm{n}}
\end{aligned}
$$

In which $a_{i j}$ is the preference rate of the $i^{\text {th }}$ element over the $j^{\text {th }}$ one; $w_{i}$ is the weight of the element $\mathrm{i}$; and $\lambda$ is a positive number. In fact the above equations can be shown as a matrix similar to the following:

$$
\mathrm{A} * \mathrm{~W}=\lambda . \mathrm{W}
$$

In which $\mathrm{A}$ is the same matrix of paired comparison; $\mathrm{W}$, the weight vector; and $\lambda$, a scalar. $\mathrm{A}$ method to calculate the special vector is by solving the equation below:

$\operatorname{det}(\mathrm{A}-\lambda . \mathrm{I})=0$ 
By solving this problem, the greatest $\lambda$ will be considered as the answer. Also by solving the matrix equation below, one can calculate each of the weights.

$$
\left(\mathrm{A}-\lambda_{\max } \cdot \mathrm{I}\right) \cdot \mathrm{W}=0
$$

For a positive and reverse matrix, such as paired comparison matrix, the special vector can be obtained through the following equation.

$$
W=\lim _{k \rightarrow \infty} \frac{A^{k} \cdot e}{e^{T} \cdot A^{k} \cdot e}
$$

We first calculate $A^{k} . e$. For instance for $\mathrm{k}=1$, we have:

$$
A^{k} . e=\left[\begin{array}{cccc}
a_{11} & a_{12} & \ldots & a_{1 n} \\
a_{21} & a_{22} & \ldots & a_{2 n} \\
\vdots & \vdots & \vdots & \vdots \\
a_{n 1} & a_{n 2} & \ldots & a_{n n}
\end{array}\right] \times\left[\begin{array}{c}
1 \\
1 \\
\vdots \\
1
\end{array}\right]=\left[\begin{array}{c}
\sum_{j=1}^{n} a_{1 j} \\
\sum_{j=1}^{n} a_{2 j} \\
\vdots \\
\sum_{j=1}^{n} a_{n j}
\end{array}\right]
$$

Now, we calculate the result of $e^{T} \cdot A^{k} . e$ :

$$
e^{T} . A^{k} . e=e^{T} .\left(A^{k} . e\right)=\left[\begin{array}{llll}
1 & 1 & \ldots & 1
\end{array}\right] \times\left[\begin{array}{c}
\sum_{j=1}^{n} a_{1 j} \\
\sum_{j=1}^{n} a_{2 j} \\
\vdots \\
\sum_{j=1}^{n} a_{n j}
\end{array}\right]=\sum_{i=1}^{n} \sum_{j=1}^{n} a_{i j}
$$

\section{Stage Two) Extracting the Priorities from the Group Comparison Table:}

To extract the priorities, we exclusively take group comparison table into consideration. To determine the priority, the concepts of normalization and weighted average are used. There are several methods for normalization. 
In AHP, normalization of the numbers of the comparison table employs the following equation: $\mathrm{rij}=\frac{\mathrm{a}_{\mathrm{ij}}}{\left(\sum_{\mathrm{i}=1}^{\mathrm{M}} \mathrm{a}_{\mathrm{ij}}\right)}$

In which rij is the normalized component?

After normalization, the rates of each level are weighted-averaged $\left(\frac{1}{N}\right)$ with the results showing the priority of each competing alternative.

\section{Stage Three) Choosing the Best Alternative}

To choose the best system, it is required to multiply the rates of each tier (related to the alternatives) by the corresponding rate of the factors, which is the same as weighted average for each alternative.

\section{Stage Four) Determining the Compatibility Rate (CR)}

Another importance of AHP is in calculating CR, which is a mechanism to determine the compatibility of the comparisons. The mechanism shows how much the priorities from the group members with the combined tables' priorities can be trusted.

Experience has shown that if the CR is less than 0.1, the compatibility of the comparisons can be accepted; otherwise, comparisons should be repeated. There have been several researches to compare the $\mathrm{CR}$, the best of which is to use the special vector.

In this method after determining the alternatives' priorities (via the logic of normalization and weighted average), the Weighted Sum Vector (WSV) is calculated (Saaty, 1994).

Accordingly, the main rates of the alternatives' comparison are multiplied by their priorities. Afterwards Compatibility Vector (CV) results from dividing each of the WSV components into the alternatives' priorities ratio to the factors. Then the average of CV (i.e. max $\lambda$ ) is calculated and accordingly compatibility index can be measured by use of the following formulae:

$\mathrm{CL}=\frac{\lambda \max -\mathrm{n}}{\mathrm{n}-1} \quad$ For individual comparisons

$\mathrm{CL}=\frac{\lambda \max -\mathrm{n}}{\mathrm{n}-1} \quad$ For group comparisons

Eventually the CR is calculated, which is: 
C.R $=\frac{C L}{\text { R.I }}$

In which R.I indicates the Random Index, extracted from the following table prepared by Saaty and Hraker (Adel Azar \& Memariani, 1995):

Table 2. RI rates for $n$

\begin{tabular}{rrrrrrrrr}
\hline $\mathrm{n}$ & 1 & 2 & 3 & 4 & 5 & 6 & 7 & 8 \\
\hline R.I & 0 & 0 & $0 / 58$ & $0 / 9$ & $1 / 12$ & $1 / 24$ & $1 / 32$ & $1 / 41$ \\
\hline $\mathrm{n}$ & 9 & 10 & 11 & 12 & 13 & 14 & 15 & \\
\hline R.I & $1 / 45$ & $1 / 49$ & $1 / 51$ & $1 / 48$ & $1 / 56$ & $1 / 57$ & $1 / 59$ & \\
\hline
\end{tabular}

\section{BACKGROUND OF AHP RESEARCHES}

There have been some researches on the way of determining the influential factors of efficiency (proficiency and effectiveness) both inside and outside the country.

Accordingly, there have been some models and methods, presented by experts, who also offered some models and methods on how to evaluate and measure efficiency.

Yet what is of account here is scientific prioritization, based on conditions and position of the organization. There have been some considerable works, concerning the use of AHP methods, though a majority of them are related to theoretic issues with practical works receiving no direct research in terms of explaining the effective factors of efficiency.

Nonetheless, the presence of some works, close to the nature and goal of the present research, have been collected which will be mentioned below.

\section{Definition of the Terms}

The current paper identifies the variants and ratios with the major role in measuring the efficiency of Mellat Bank's branches in Semnan. In order to identify them, bank-based texts and literatures 
have gone under study and an index of effective variants and rations for measuring the efficiency of the bank's branches have been extracted. The most important items under study are as below. Special Vector: Another technique of weight measurement (wi) in case of no complete constancy for a matrix. It can be regarded as a relative method that can be interpreted as a simple averaging process, so that the final vector of $\mathrm{w}$ results from averaging all possible ways to compare the indices with one another; therefore, special vector is a natural method to measure the weights and one of the appropriate methods to determine the priorities for the existing indices (or alternatives) (Asghar Pour, 1998).

Bank: A profitable institute which with its capital or customers' deposits, collects deposits, gives loans and credits, and offers bank services in order to benefit (Ahmad Mojtahed \& Ali Hassan Zadeh, 2005).

\section{Hierarchy Analysis}

\section{Methodology}

The importance of each of the effective variants and ratios for measuring the bank branches' efficiency has been measured via survey method by means of questionnaires.

In order to identify the effective variants in measuring the efficiency of banks' branches for use in border methods, initially a comprehensive list of variants should be selected based on specific texts and surveyed as a pilot study.

Then in order to evaluate and validate them in Iranian environmental conditions, the opinions of high-ranking managers of Mellat Bank have been collected via Delphi Method by means of questionnaire, which resulted from two stages of distribution and consensus about the variants among the experts of Mellat Bank in Semnan.

Furthermore, to identify the important ratios of measuring the efficiency of bank's branches for use in financial proportions method, at first a comprehensive list of ratios was selected based on specific texts and was pilot studied. Afterwards, in order to evaluate their validity in Iranian environmental conditions, the opinions of high-ranking managers of Mellat Bank were collected via questionnaire. Then the weight of each index was determined by means of special vector 
method. After identifying the important ratios as well as weighting, in the next stage the AHP of importance coefficient for each of them was determined and ranked via the questionnaire.

\section{Statistical Population and Sample}

The statistical population of this research includes the experts (managers, experts, and branch managers) of Mellat Bank in Semnan, of which a sum of 84 people were selected in random. In the first stage, 65 questionnaires were received, of which 57 were acceptable. Table 3 shows the number of distributed, answered, and acceptable questionnaires for the first and second stages.

\section{Demography of the Answerers}

General information of the answerers, extracted from the questionnaire, is broken down into their posts, academic degree, field of study, and experience. Considerable points, concerning this general information, can be seen in Table 4 and 5 .

Table 3. Number of questionnaires of the two stages

\begin{tabular}{rlrll}
\hline Second stage's delphi & First stage's delphi & & Type \\
\hline 23 & & 50 & All & distributed \\
& & & questionnaires \\
\hline 15 & 31 & Answered questionnaires \\
\hline 6 & 23 & Acceptable questionniares \\
\hline
\end{tabular}

Table 4. Classification of the answerers, according to the post in both stages

\begin{tabular}{rrrrrl}
\hline \multicolumn{1}{l}{ Second Stage } & \multicolumn{2}{l}{ First Stage } & \multicolumn{2}{l}{ Post } \\
\cline { 2 - 4 } \multicolumn{1}{l}{ Percent } & Number & Percent & Number & \\
\hline 33 & 2 & 22 & 5 & Branch manager \\
\hline 50 & 3 & 52 & 12 & Bank expert \\
\hline 17 & 1 & 17 & 4 & Academic \\
\hline 0 & 0 & 9 & 2 & The rest \\
\hline 100 & 6 & 100 & 23 & Sum \\
\hline
\end{tabular}


Table 5. Classification of the answerers, according to work experience in both stages

\begin{tabular}{rrrrl}
\hline Percent & Number & Percent & Number & \\
\hline 0 & 0 & 8.5 & 2 & Less than 5 years \\
\hline 17 & 1 & 22 & 5 & From 5 to 10 years \\
\hline 66 & 4 & 61 & 14 & From 11 to 15 years \\
\hline 17 & 1 & 8.5 & 2 & More than 15 years \\
\hline 100 & 6 & 100 & 23 & Sum \\
\hline
\end{tabular}

\section{Questionnaire's Validity and Reliability}

In order to measure the trustworthiness or reliability of the measurement tool (i.e. the questionnaire), the present research tested two reliable aspects, having used scientific methods and techniques. These include: 1) measurement stability, concerning all items and 2) stability of the given answers concerning each item (Pour Heidari, 2002).

For determining the former Cronbach's Alpha was used for first and second stages' questionnaires. It showed that both questionnaires had an acceptable reliability.

Table 6. Determining the stability of measurement results in both stages

\begin{tabular}{lrr|r|r|r}
\hline $\begin{array}{l}\text { Cronbach's } \\
\text { Coefficient }\end{array}$ & Alpha & $\begin{array}{l}\text { Number of questions } \\
\text { Number of }\end{array}$ & $\begin{array}{l}\text { complete } \\
\text { questionnaires }\end{array}$ & Questionnaire \\
\hline & $0 / 9095$ & 41 & 23 & First Stage \\
\hline $0 / 8703$ & 12 & 6 & Second Stage \\
\hline
\end{tabular}




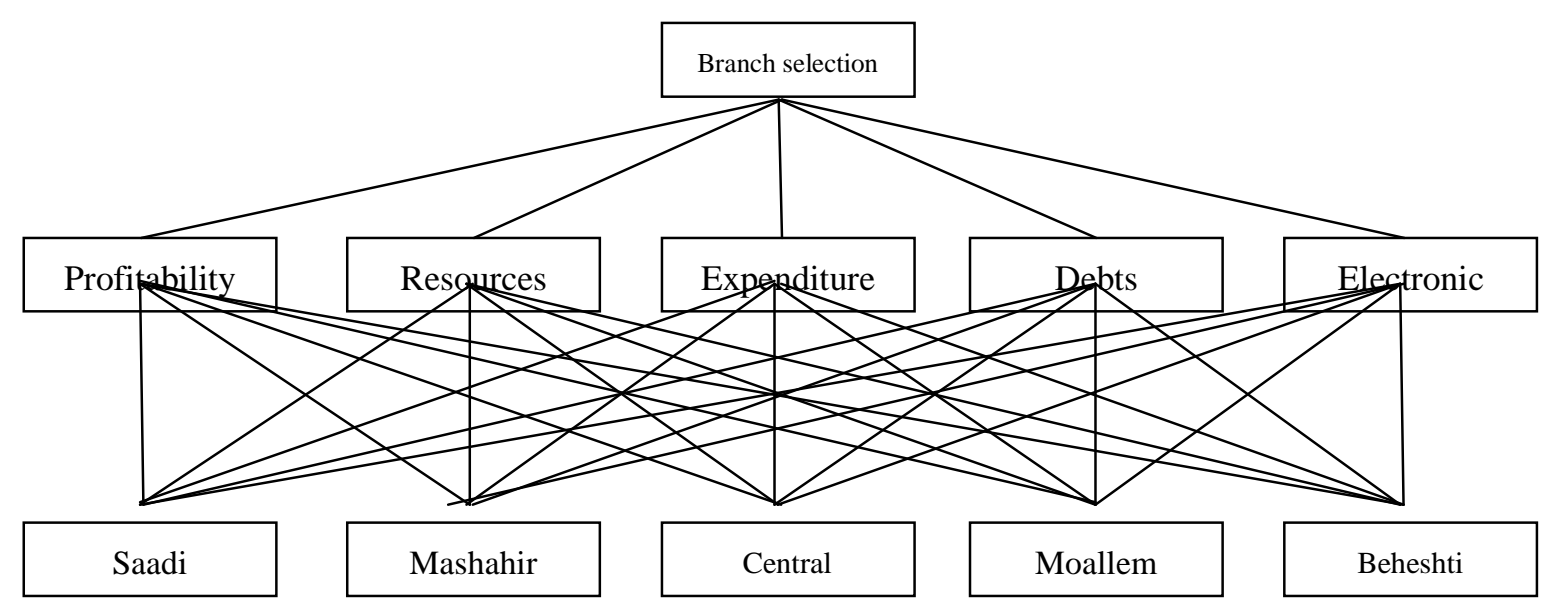

\begin{tabular}{|c|c|c|c|c|c|c|}
\hline Indices & Profitability & & Resources & Expenditure & $\begin{array}{l}\text { Overdue } \\
\text { debts }\end{array}$ & $\begin{array}{l}\text { Electronic } \\
\text { services }\end{array}$ \\
\hline Profitability & 1 & 3 & & 5 & 8 & 9 \\
\hline Resources & $\frac{1}{3}$ & 1 & & 4 & 6 & 7 \\
\hline Expenditure & $\frac{1}{5}$ & & $\frac{1}{4}$ & 1 & 4 & 5 \\
\hline $\begin{array}{r}\text { Overdue } \\
\text { debts }\end{array}$ & $\frac{1}{8}$ & & $\frac{1}{6}$ & $\frac{1}{4}$ & 1 & 2 \\
\hline $\begin{array}{r}\text { Electronic } \\
\text { services }\end{array}$ & $\frac{1}{9}$ & & $\frac{1}{7}$ & $\frac{1}{5}$ & $\frac{1}{2}$ & 1 \\
\hline
\end{tabular}

$D^{\prime} . e=\left|\begin{array}{c}2 \epsilon \\ 18 / \\ 10 / 1 \\ 233 \\ 18 / 45 \\ 10 / 44 \\ 0 / 5 \\ 1 / 95\end{array}\right|$

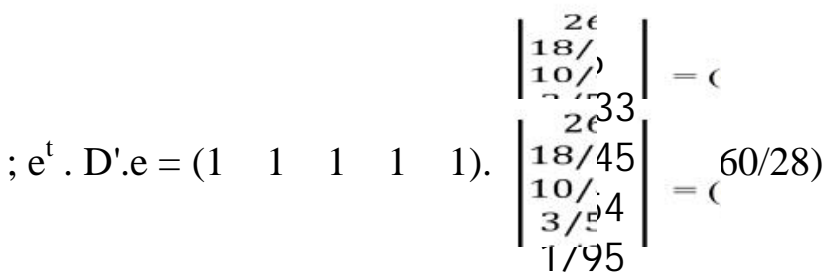

$\underset{\rightarrow}{\text { Therefore }} \quad \mathrm{w}^{\prime}=\mathrm{D}^{\prime} . \mathrm{e} / \mathrm{e}^{\mathrm{t}} . \mathrm{D}^{\prime} . \mathrm{e}==(0 / 4311,0 / 304,0 / 1742,0 / 05886,0 / 0331)$

Squares are used for Matrix D, i.e.:

$\mathrm{D}^{2}=\mathrm{D} . \mathrm{D} \quad$ :

$\mathrm{W}^{5}=\mathrm{D}^{5} \cdot \mathrm{e} / \mathrm{e}^{\mathrm{t}} \cdot \mathrm{D}^{5} \cdot \mathrm{e}=(0 / 4313,0 / 3041,0 / 1733,0 / 05875,0 / 0324)$ 
It can be seen that the process' convergence has happened in the fifth transfer and the calculation has reached stability, i.e. $\mathrm{w}^{5}$ indicates the final vector, determining the weights for the existing indices.

Moreover, "special vector" determines a natural calculation of incompatibility degree of the existing information in a Matrix D as below:

C.I $=\frac{\lambda_{\max }-\mathrm{n}}{\mathrm{n}-1}$

$\mathrm{D} . \mathrm{W}=\left|\begin{array}{lllll}1 & 3 & 5 & 8 & 9 \\ \frac{1}{3} & 1 & 4 & 6 & 7 \\ \frac{1}{5} & \frac{1}{4} & 1 & 4 & 5 \\ \frac{1}{8} & \frac{1}{6} & \frac{1}{4} & 1 & 2 \\ \frac{1}{9} & \frac{1}{7} & \frac{1}{5} & \frac{1}{2} & 1\end{array}\right| \begin{aligned} & \mathbf{0} / 4 \\ & 0 / 3313 \\ & 0 / 1313 \\ & 0 / 7341 \\ & 0 / 3733 \\ & 0 / 1 \\ & 0 / 0_{587} \\ & 0 / 0324\end{aligned}\left|=\begin{array}{l}2 / 9 \\ 1 / 7723 \\ 0 / 7 \\ 2 / 9208 \\ 1 / 7328 \\ 0 / 7 \\ 0 / 2715 \\ 0 / 1878\end{array}\right|$

Since we have: $\mathrm{D} . \mathrm{W}=\lambda . \mathrm{W}$, for the calculation we will have:

$\lambda . \mathrm{w} \div \mathrm{w}=\lambda$

$\begin{aligned} & 2 / 9 \\ & 1 / 7723 \\ & 0 / 7723\end{aligned}|\cdot| \begin{aligned} & 0 / 4 \\ & 0 / 33313 \\ & 0 / 1\end{aligned}|=| \begin{aligned} & 6 / 8 \\ & 5 / 691 \\ & 4 / 2 \\ & 2 / 9208 \\ & 1 / 7328 \\ & 0 / 7735 \\ & 0 / 2715 \\ & 0 / 1878\end{aligned}|\cdot| \begin{aligned} & 0 / 431 \\ & 0 / 3733 \\ & 0 / 1587 \\ & 0 / 0 \\ & 0 / 0324\end{aligned}|=| \begin{aligned} & 6 / 858 \\ & 5 / 627 \\ & 4 / 221 \\ & 5 / 795\end{aligned} \mid$

Thus we have: $=5 / 438 \lambda_{\max }$

$\stackrel{\text { Thus }}{\rightarrow}$ C.I $=\frac{5 / 438-5}{5-1}=0 / 1095$

Matrix results will be accepted.

$$
\text { C.I }=\frac{C . I}{R . I} \Rightarrow \frac{0 / 1095}{1 / 12}=0 / 097 \leq 0 / 1
$$

In this section, we determine the relative weights of the alternatives for each index, by means of paired comparison matrices obtained from the previous stage. 


\begin{tabular}{|c|c|c|c|c|c|c|c|c|}
\hline Profitability & Saadi & & Mashahir & Central & & Moallem & & Beheshti \\
\hline Saadi & & 1 & & 2 & & & & \\
\hline Mashahir & & & & 1 & & & & \\
\hline Central & & 7 & & 8 & 1 & & 3 & \\
\hline Moallem & & 5 & & 6 & & & 1 & \\
\hline Beheshti & & 6 & & 7 & & & 3 & \\
\hline
\end{tabular}

Profitability $\mathrm{W}=(0 / 0620,0 / 0342,0 / 3710,0 / 2238,0 / 3091)$

$$
\text { C.R }=0 / 0716 \leq 0 / 1
$$

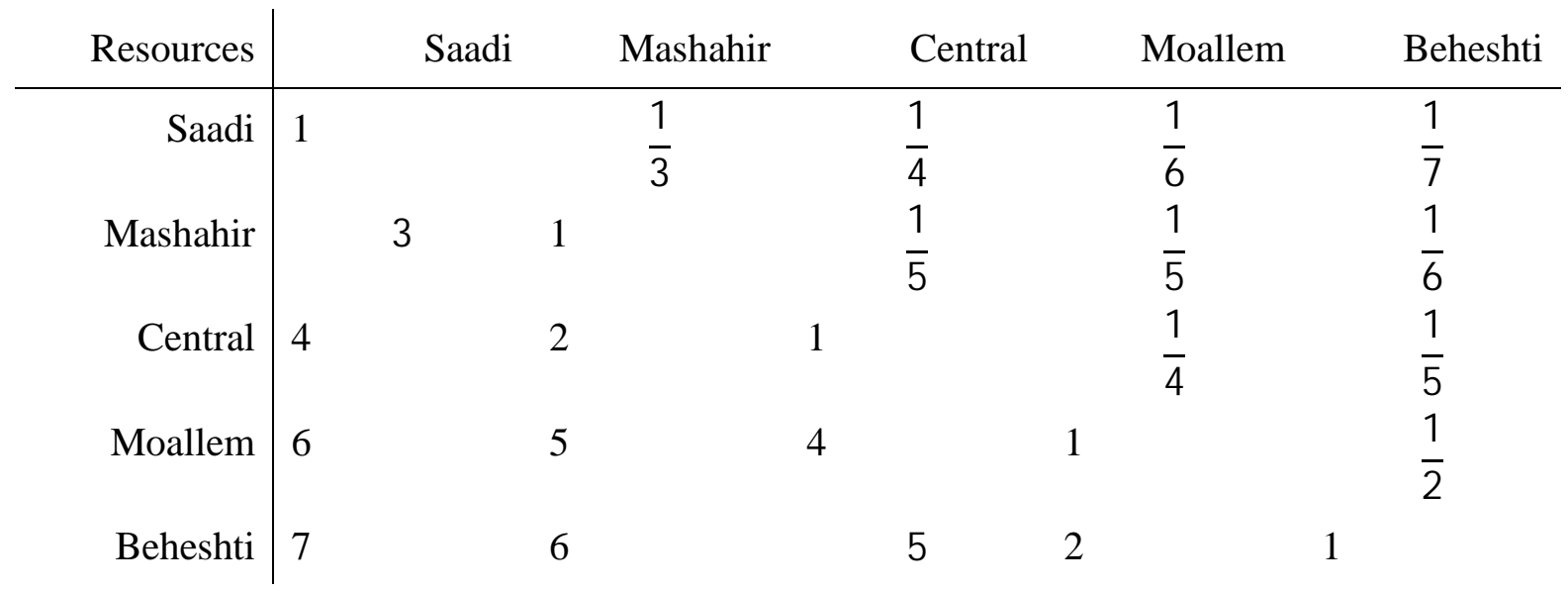

Resources W= $(0 / 0366,0 / 0941,0 / 1441,0 / 3191,0 / 4061)$

$$
\text { C.R }=0 / 0723 \leq 0 / 1
$$




\begin{tabular}{r|rcccr}
\hline Expenditure & Saadi & Mashahir & Central & Moallem & Beheshti \\
\hline Saadi & 1 & & & \\
Mashahir & 4 & 1 & 1 & 1 & 6 \\
Central & 6 & 3 & 2 & & 7 \\
Moallem & 7 & 6 & & & 1 \\
Beheshti & 2 & & &
\end{tabular}

Expenditure $\mathrm{W}=(0 / 0377,0 / 1739,0 / 3021,0 / 4211,0 / 0652)$

$$
\text { C.R }=0 / 0851 \leq 0 / 1
$$

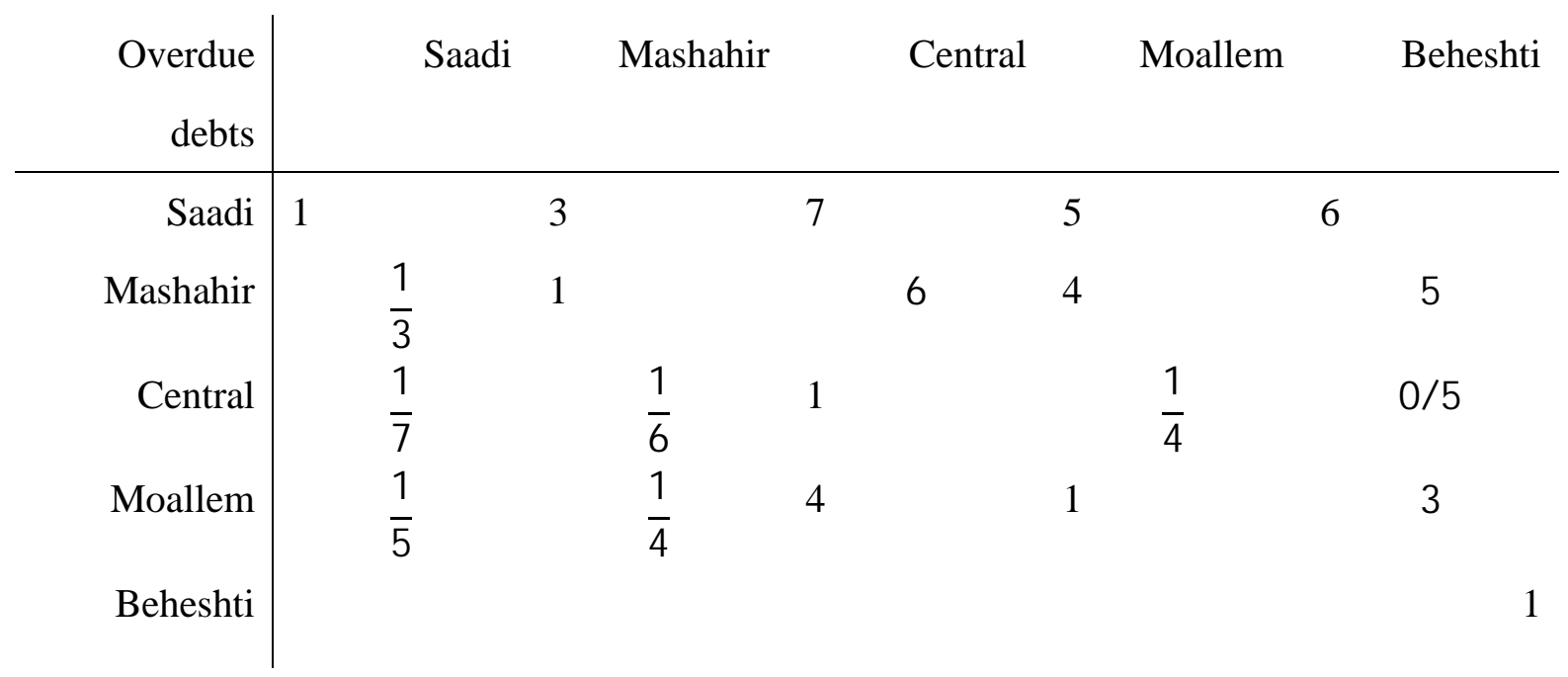

Overdue debts $\mathrm{W}=(0 / 4187,0 / 3109,0 / 0392,0 / 1608,0 / 0704)$

$$
\text { C.R }=0 / 0907 \leq 0 / 1
$$




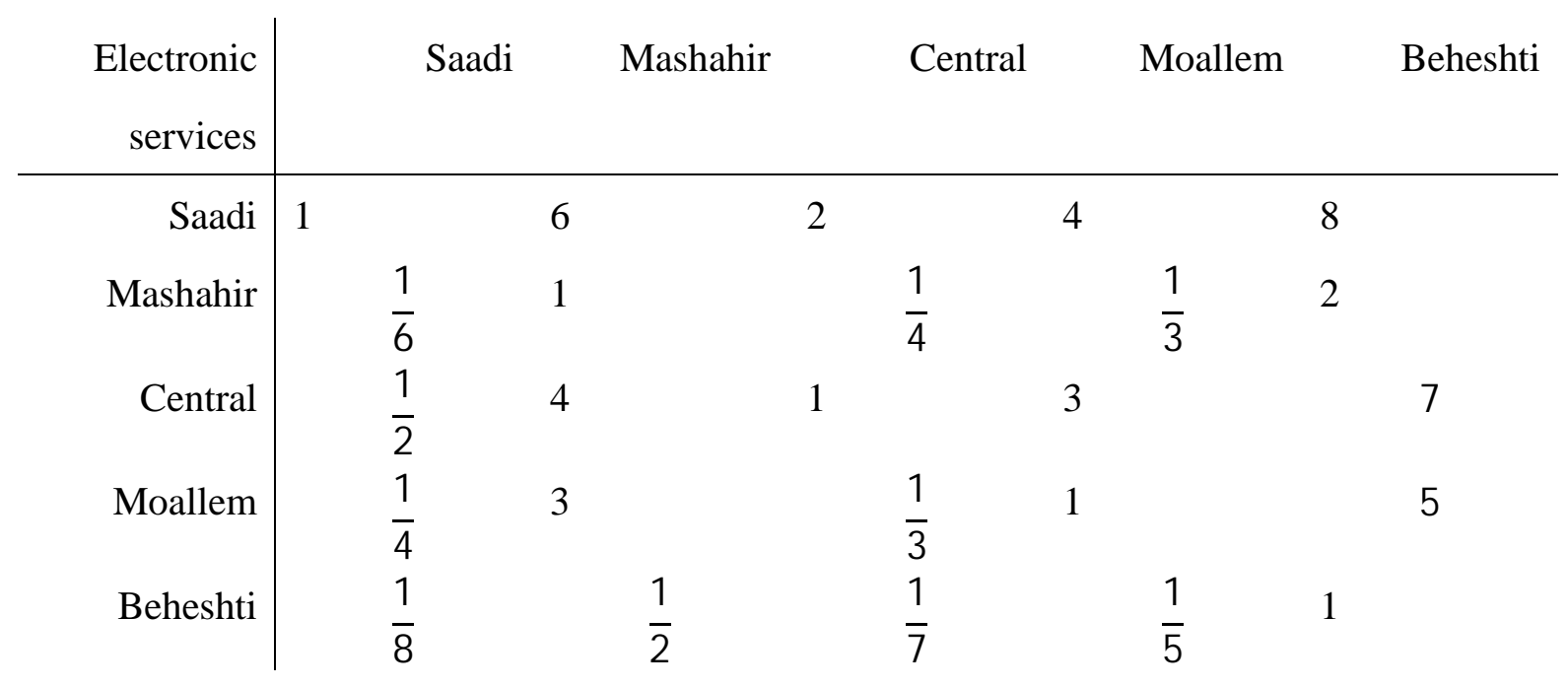

Electronic services $W=(0 / 4054,0 / 0724,0 / 2992,0 / 1850,0 / 0380)$

$$
\text { C.R }=0 / 0407 \leq 0 / 1
$$

Saadi $=0 / 0620(0 / 4313)+0 / 0366(0 / 3041)+0 / 0377(0 / 1734)+0 / 4187(0 / 0588)+$ $0 / 4054(0 / 0324)=0 / 082$

Mashahir $=$ 0/0342(0/4313) + 0/0941 $(0 / 3041)+0 / 1739(0 / 1734)+0 / 3109(0 / 0588)+0 / 0724$ $(0 / 0324)=0 / 094$

Central $=0 / 3710(0 / 4313)+0 / 1441(0 / 3041)+0 / 3021(0 / 1734)+0 / 0392(0 / 0588)+0 / 2992$ $(0 / 0324)=0 / 268$

Moallem $=0 / 2238(0 / 4313)+0 / 3191(03041)+0 / 4211(0 / 1734)+0 / 1608(0 / 0588)+0 / 1850$ $(0 / 0324)=0 / 282$

Beheshti $=0 / 3091(0 / 4313)+0 / 4061(0 / 3041)+0.0652(0 / 1734)+0 / 0704(0 / 0588)+0 / 0380$ $(0 / 0324)=0 / 274$

Table 7. Branches' prioritization

\begin{tabular}{rrrrrl}
\hline Saadi & Mashahir & Central & Beheshti & Moallem & Branch name \\
\hline 5 & 4 & 3 & 2 & 1 & Rank \\
\hline
\end{tabular}




\section{CONCLUSION AND RECOMMENDATION}

In order to continuously improve the proficiency, or in better and more comprehensive words, efficiency, a four-stage process should be established. The first step is scheduling, which is mentioned by two aspects: long-term and short-term scheduling where the goals, activities, and necessary measures are identified.

Then, these schedules go into execution. Afterwards it is the turn of measurement where the resultant changes should be measured, yet before that it is necessary to plan the known and measureable criteria and standards in each context. This stage is of considerable account, requiring expertise more than other stages.

Later, based on the resultant data from this stage, the results are evaluated where the results are compared with the goals, set in the schedules. Also the weakness will be identified and all will be rescheduled. This process is repeated like an organized cycle.

Based on what was abovementioned, results of the present research are important in terms of scheduling. In fact it can be said that these results pertain to the starting point. Thanks to them, it will be clarified that scheduling should be performed for which factors and with what priorities. Hence, officials of the bank should take other stages into serious consideration in order to achieve the ultimate goal (continuous improvement of the efficiency).

This research employed AHP, which was the more efficient than other MADM methods. It was selected as the best method to determine and explain the effective factors of efficiency in branches of Mellat Bank in Semnan. Therefore, based on what was abovementioned, some future recommendations are offered both in terms of efficiency and researching.

Modern organizations operate in a turbulent and competitive environment and even for their survival need to determine their own weaknesses and strengths in order to ascertain achieving the essential goals of the organization. One of the most important tools in modern theories of management to achieve this need is methodologies of performance evaluation (individual, process-based, and organizational) and one of the challenges of different models and frameworks 
of performance evaluation is to extract the indices, required for the evaluation. Hence the majority of experts believe that great managers should not get involved with a significant number of indices, based on their tastes.

Since a bulk of criteria will have less impact and benefit for controlling goals, an amount is needed for the indices to monitor the general status of the organization. Indices of AHP model possess this trait.

The model, presented in this research, turns the organization's performance to an intelligent controlling system, in accordance to its goals and strategies in five aspects of electronic service, debts, expenditure, resources, and profitability.

Sensitivity in performance evaluation sometimes appears when determining the best strategy among those, faced by the management. Based on the results from choosing a strategy by the model in the best and most accurate way available, elite mangers can select the most efficient and best factors, influential on efficiency.

Mellat Bank as well as other banks and financial institutions in Iran, which in the turbulent environment of the market always are in need of designing, acting, and evaluating their own efficiency, can use this model, not only to evaluate their efficiency correctly and logically, but to predict the bank's performance in accordance with future decisions.

Now at the end some suggestions are offered which will play a significant role in the improvement of management in Iran and banks' group.

It is hoped that by using these suggestions, my colleges with the help of expert university professors be able to take influential steps for industry.

1) It is suggested that in order to continue this research or similar ones, after weighting the evaluated indices, restudy the determined weights by experts and elites. In case of approving these experts by the experts and elites, the process of efficiency evaluation should be explained and then the indices, selected by the balanced score card model, should be measured. Afterwards the efficiency, evaluation, etc. must be interpreted and the results must be compared. Eventually a general review should be done from the organization's processes. 
2) Used models and methodologies in this research can be easily executed in all organizations of the country. Thanks to multi-index decision-making models and with regards to their own conditions and operation system, these organizations can identify and prioritize the factors, influential on their own efficiency.

3) A set of criteria and standards for influential factors of the efficiency of Mellat Bank's branches in Semnan should be prepared in a way so that with them efficiency changes can be evaluated and measured correctly. Accordingly, one should consider that the criteria and standards have necessary traits such as being scientific, measurability, understandability, having reliability, etc.

4) Merely depending on inputs and outputs, prepared by the bank, cannot separate efficient and non-efficient branches well. Therefore, it is suggested that apart from quantitative information, prepared by the bank, experts' ideas concerning the branch's commercial position, geographical position, risk status, etc. should be used when measuring the bank's branches' efficiency.

\section{REFERENCES}

[1] Azar, Adel and Memariani, Azizollah, “AHP, a Modern Technique for Group Decision Making”, Management Science, No. 28, 1995.

[2] Asghar Pour, Mohammad Javad, "Multi-Criterion Decision Making”, Tehran, University of Tehran Publication, 1998.

[3] Pour Heidari, Omid, "Surveying and Explanation of Information Needs and Priorities of Managers in Long-Term Projects' Decisions, PhD dissertation, University of Tehran, Faculty of Management, 2002.

[4] Thomas L. Saaty, "Decision Making for Managers", trans. Ali Asghar Tofigh, Tehran, Industrial Management Organization, 1999.

[5] Hafez Nia, Mohammad, “An Introduction to Research Methodology in Humanities”, Tehran, Samt Publication, 1998. 
[6] Sarmad, Zohreh; Bazargan, Abbas; Hejazi, Elahe, "Methods of Researching in Behavioral Sciences", Agah Publication, 1997.

[7] Abedi Pezhman, "Estimating the Technical Efficiency of Banking Industry in Iran", Allameh Tabatabyi University, MA thesis in economy, autumn, 1998.

[8] Emadi, Meysam, "Designing Strategic Program and Prioritization of Selected Strategies in SWOT Matrix by Means of Fuzzy TOPSIS”, Semnan Islamic Azad University, February 2007.

[9] Ahmad Mojtahed and Ali Hassan Zadeh, "Money and Banking and Financial Institutions", Tehran: Monetary and Banking Research Center, Central Bank of Islamic Republic of Iran, 2005.

[10] Schaffnit, Rosen, Paradi (1997) Best Practice analysis of bank branches: An application of DEA in a large Canadian bank. European Journal of operational research 98 p p 270-90.

[11]Thomas F Sierns, Richard S Barr (1997) DEA/AR Profit ratios and Sensitivity of 100 Large u.s. ba.

\section{How to cite this article:}

Hemmati Y and Danaei A. Prioritization of Mellat Bank's Branches in semnan by means of analytical hierarchy process (AHP) and weight calculation technique of special vector. J. Fundam. Appl. Sci., 2016, 8(3S), 430-451. 